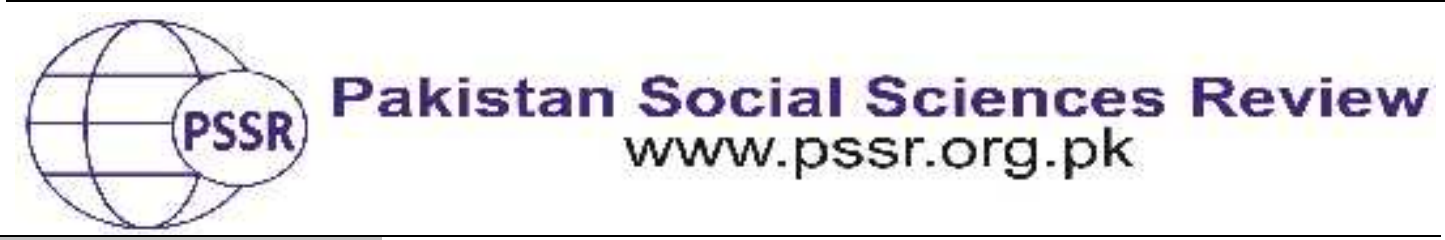

RESEARCH PAPER

\title{
Evaluation of the English Curriculum on the Basis of Linguistics Skills Approved for Higher Secondary Level Public Institutions of Karachi
}

\author{
Muhammad Asif * 1 Prof. Dr. Ahmad Saeed ${ }^{2}$ Dr. M Akhtar Kang ${ }^{3}$
}

1. Research Scholar, Faculty of Humanities \& Social Sciences, Hamdard University, Karachi, Sindh, Pakistan

2. Research Supervisor, Faculty of Humanities \& Social Sciences, Hamdard University Karachi, Sindh, Pakistan

3. Faculty of Humanities \& Social Sciences, Hamdard University Karachi, Sindh, Pakistan

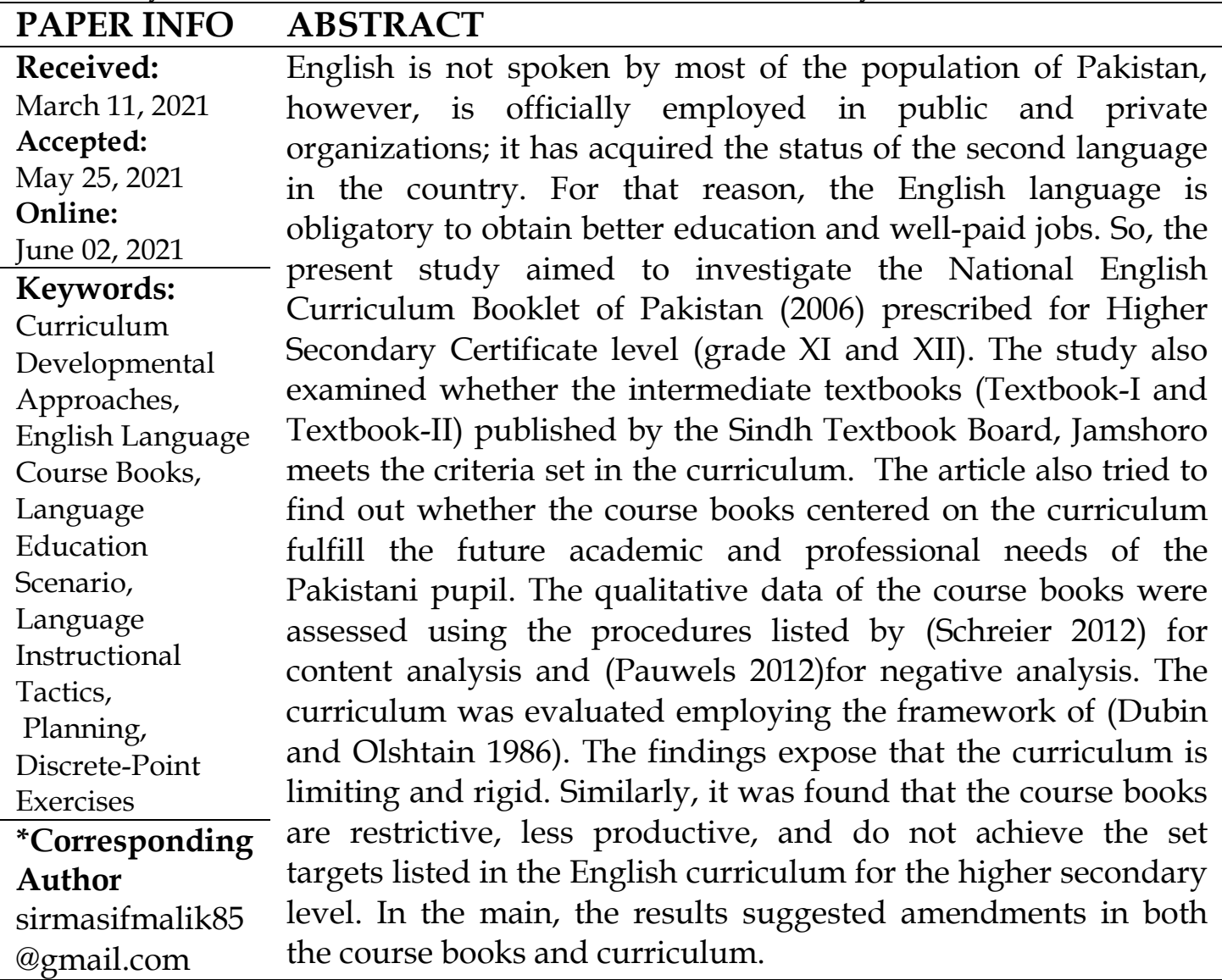

\section{Introduction}

It is an irrefutable truth that a language is a tool for connecting people of diverse cultures, dialects, colors, and races. English is considered the most prevalent language of this century. It is recognized as a global language that is utilized in 
official talks like social, political, economic, and sports conferences. The present era saw a growing demand for English as machinery flourishes with the English directions labeled on nearly all the industrial products. Thus, it is essential to study the English language as it is necessary for communique and progress. One method to learn the language is through the academic system that targets to familiarize people with advancements and innovations in the field of the English teaching-learning process.

The academic system is liable for incorporating the English language in the daily life of individuals by means of stepping from the basic levels at schools to higher levels at colleges and universities in an organized manner. This can only be attained through a well-planned curriculum that fulfills the needs of a particular nation. A curriculum is a set of courses through that a nation tries to accomplish a better future. It is based on experiential and educational researches. The curriculum should consist not only of knowledge and facts but also present innovations and skills. The constituents of the curriculum (i-e, objectives, instructional methods, and evaluation) should be integrated and these must be entities of perpetual modification. Curriculum analysis is thought to be a vital part of the process of designing and implementation. Curriculum developmental process will be ambiguous without analysis and justification of proposals because comprehensive evaluation provides educators with strengths and shortcomings that appear during implementing and planning stages (White 1988).

The assessment procedure covers diverse areas of the curriculum; generally, the contents offered by course books. Even if the course book is not the only instrument for instructional practice, it has a significant influence on attaining the language learning goals. As instructors find difficulty in designing their teaching materials in the given insufficient time that limits their proficiency, it emphasizes the practice and effectiveness of the course book to reimburse the loss of genuine materials (Ansary \& Babaii, 2002). The course book should contain modern themes so that it can stay even with the world developments and can fulfill the needs of the recent era. Since regarded as a basic pillar of the instructional process, the course book improvement leads to the improvement and advancement of the curriculum in a country like Pakistan where English is spoken as a second language. The Pakistani students depend chiefly on textbooks to enhance knowledge and improve language skills. Hence, course book analysis should also be taken into account by educators and curriculum developers.

The present study aims to investigate the National English Curriculum Booklet of Pakistan (NECBP) prescribed for Higher Secondary Certificate (HSC) level (grade XI and XII). The study will also examine whether the intermediate textbooks (Textbook-I and Textbook-II) published by the Sindh Textbook Board, Jamshoro meets the criteria set in the NECBP 2006. 


\section{Language Curriculum}

\section{Definitions of Curriculum and Syllabus}

A curriculum for any language is a sort of academic program which contains general objectives and standards associating with language teaching-learning methodology. Whereas, the syllabus includes specific goals, teaching contents and classroom tasks (Xiaotang, 2011).

\section{Varied Models of Curriculum}

It is an integral part of the research to find appropriate evaluation criteria. For this reason, the following curriculum assessment models were reviewed.

\section{The Content Model}

This model focuses on the contents of the curriculum. The primary aim of language instruction is to transfer information related to the form of a language including grammatical and lexical items. Finney claims that this approach is very simple as it states that language is a set of predetermined rules and it overlooks aspects for instance "proper usage of language, different approaches of discourse" or pupils' need (Finney, 2002).

\section{The Product Model}

The product model is characterized by the focus on the achievement of target goals (Dubin \& Olshtain, 1986); (Finney 2002). Dubin and Olshtain (1986) have divided target goals into two categories whichare, proficiency-based-goals (stress on realistic application of language) and information-based-goals (stress on attaining accuracy and usage of discrete features of grammar). But some other language experts have included three additional approachestothe product model. The approaches are as under:

\begin{tabular}{|c|c|c|}
\hline SIRICTIRAL APPROACH & SITLATIONAL APPROACE & NOTIONALITNCTIOSAL APPROACH \\
\hline Fo:uses on graminatical iters & \multirow{3}{*}{ 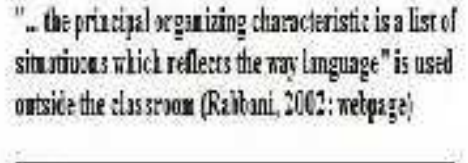 } & \multirow{3}{*}{ 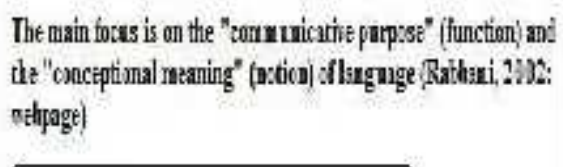 } \\
\hline Wealdosses: & & \\
\hline 1, Onil fouses as one aspectel & & \\
\hline language - its granmar & Athinigge: & \multirow{4}{*}{ 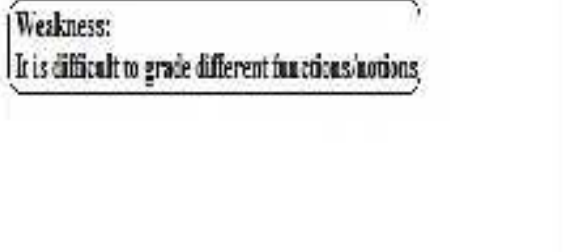 } \\
\hline 2) Dificiclt no take inm sccount the & Lamer-centred & \\
\hline speken unfrrinta discourse. & |Trakızs: & \\
\hline & 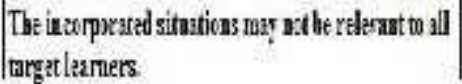 & \\
\hline
\end{tabular}

Figure 1 (Adapted from Rabbani, 2002) 


\section{Three Additional Approaches of Product Model}

\section{The Process Model}

The process model deals with language education strategies. This pliable model emphasizes the necessities and interestsof the pupils; it also focuses on tasks. But then again the model is not considered convincing and thus it is not included in the curriculum development system (Smith, 2000); (Rabbini, 2002) \& (Finney, 2002).

\section{Mixed Approach to Design Curriculum}

Smith (2000), Rabbini (2002) and Finney (2002) have suggested an integrated methodology to design curriculum (that includes the features of both process and product model).

\section{Material Evaluation}

According to the Cambridge dictionary, "evaluation" means to judge the worth, significance, or quality ofsomething.However, Oxford describes it as "to form an idea of the amount, number or value of something" (Nazeer, Shah, \& Sarwat 2015) state that evaluation is an organized method of accumulating and inferring data to make future decisions. Evaluation helps to improve not only the present educational scenario but also provides room for future development. Evaluation is, therefore, a method of assessing the significance,strength, and shortcomings of something. Accordingly, course book evaluation is concerned with the analysis of the significance, quality, value, strength, and shortcomings of the basic instructional material (textbook) used in the educational system (Nazeer, et. al. 2015). The practice of using a textbook in education is highly valued but the scenario worsens sometimes when instructors rely on their course booksand do not utilize other instructional sources. All the course books possibly will not achieve the targets of the course. There will occur several inadequacies as (Grant, 1987) points out that one cannot find a textbook that can be regarded as perfect. For that reason, it is of prime importance that course books should be assessed before utilizing in an educational system. In the same way, Nazeer, et. al. (2015) believes that evaluation of the English instructional material is essential to determine the significance and quality and to what extent it achieves the set goals and objectives in pedagogy (Nazeer, Shah and Sarwat 2015, 63). Therefore, it could be said that the course books are assessed to discover how much they are applicable for a designed course.They are also assessed to enhance their worth and to make them appropriate for attaining pre-set goals. Conversely, Cunning worth (1984) thinks that there is not a single course bookthat can be appropriate for a specific educational context. Some of its sections may not fulfill the requirement of a specific course (Cunningworth, 1984). 


\section{English Course books in Pakistani Context}

The English language is used worldwide because of being the language of science and technology. The language is also employed in education globally because of its status as lingua franca.Several countries prefer English as a medium of instruction in academics. Graddol (1997) believes that 2 billion people will be speaking English in the coming decades (Graddol 1997, 2). English is a language of higher education in Pakistan. It is also a medium of instruction at the school level in most of the big cities but local languages are utilized in the rural areas. Aftab (2011) states that English is given the status of the second language, however, an insignificant number of people speak it in Pakistan. It is for this reason that English is only employed in written form in official documents, magazines, books, advertisements, etc. excluding the people of the upper class who use it in their daily life (Aftab, 2011). Akram and Mahmood (2007) claim that English is regarded as a high-status language due to its usage in the public sector, business, higher education, and law in Pakistan.Urdu is the national and official language but English is esteemed as the co-official language of the country(Akram and Mahmood 2007, 48). English is regarded as a key to success in Pakistan for acquiring higher education and well-paid jobs.Earlier, English was taught as a compulsory subject from VI class to Bachelors level in the country, however, as the demand for the English language increased globally, the Ministry of Education Pakistan (MEP) decided to teach English as a compulsory subject at the elementary level as well (NECBP, 2006). Nowadays, English is not only taught as a subject but also it has become an instructional medium for different subjects. But the fact is that all of these policies have not yet produce desired results. The NECPB 2006, which is presently employed,states that the current English curriculum for class I to XII has been designed carefully after comprehensive research and cooperation with language professionals from all over the country (ibid: 2006,3). Moreover,it also assures that the standards and proficiencies offered in the curriculum will help in enhancing the quality of English language education in Pakistan. However, Aftab (2011) believes that the approved English course books in Pakistan are ineffective for enhancing language skills and the English instructional standard is also not satisfactory (Aftab 2011, 322). While Akram and Mahmood (2007) state several reasons fornot attaining the defined objectives that include outdated material with the bulk of mechanical and controlled activities, teaching language through literature instead of the functional approach, untrained English teachers with no awareness of contemporary instructional techniques, no teacher training or workshops, content analysis sort of examination rather than assessing language skills, the dearth of instructional resources and overloaded classes (Akram \& Mahmood 2007).

\section{Evaluation Methods}

Several scholars have indicated numerous methods for course book evaluation. Naseem, Shah, and Saima (2015) have divided course book analysis into three categories in their study which are based on research, processing, and inferring of data (Nazeer, et. al. 2015). These are theoretical assessment, empirical assessment, 
and statistical method. On the other hand,McGrath (2002) also presented three different procedures to assess the course book which are:an impressionistic method, checklist method, and in-depth method. The first method, as the name proposes, examines the course booksuperficially.It acquiresa general idea of the learning content. An assessor rapidly takes a general idea of a textbook by having a look at the first and the last pages, content, and other features. In the second suggested method, a textbook is evaluated through a list of chosen items. A Likert or rating scale is also employed in this method. He emphasizes the need to use the checklist method before starting a course. The checklist has many benefits since it is organized, inexpensive, unambiguous, and convenient. According to McGrath (2002), the in-depth technique is employed when the assessor needs to undertake a comprehensive analysis of the course book. He recommends that the Englishcourse books should be evaluated before and after a program to achieve desired goals (McGrath, 2002).

\section{Instructional Material}

Both the chosen course books (IETO and IETT) are based on NECBP 2006. The NECBP 2006 consists of Students Learning outcomes (SLOs), competencies, benchmarks, and standards. Competencies are further categorized into five sections which are 1) Conversational skills, 2) Writing Skills, 3) Reading and creative skills, 4) proper moral and social growth, and 5) formal and lexical features of language (NECBP, I-XII, 2006, 7).Since the selected course booksare based on the NECBP 2006therefore these books must accomplish the targeted goal.

\section{Material and Methods}

\section{Research Design}

Tobin (2010) states that a descriptive case study approach is thorough and focused and in this type of approach issues are scrutinized carefully (Tobin 2010). Therefore, this method is employed in the present study taking NECBP 2006 as a case. This technique is more reliable in the domain of analyzing language policy like curriculum assessment (Crowe, et. al. 2011).

\section{Data Collection}

The study aims to investigate the curriculum booklet approved for the HSC level schools and colleges in Karachi, Sindh. The NECBP 2006 can easily be found on the internet. The booklet is proposed for the learners from elementary to higher secondary level(class I -XII). The document is categorized into eight parts; every part explains the different educational features. The sections contain "background, curriculum developmental procedures, SLOs, kind of texts and themes, teaching strategies, assessment, and directions for language course designers and instructors training" (NECBP, 2006). 
The empirical data was also collected with the data from the curriculum. The empirical data is comprised of the perceptions of 15 HSC level English teachers. For this purpose, five dissimilar intermediate public colleges of Karachi were selected through purposive sampling. For the instructors' interviews, structured questions were employed (questions were adopted from (Aftab, 2011) permission was thankfully granted to use the tool via email). Their views were concerned with the characteristics involved in the language teaching-learning process.

\section{Data Analysis}

The qualitative data was assessed using the procedures listed by Schreier (2012, 190-191) for content analysis and Pauwels (2012, 253)for negative analysis. The curriculum was appraised employing the framework of Dubin and Olshtain (1986, 77) [see Appendix A below].The content evaluation was chosen as it is the best way to comprehend the language of the text and the author's viewpoint(Berg 2001,37). In this way, the focus is on the reflective meaning stated by the text instead of superficial content, that is, the content which is simply traceable in the composition (Dörnyei, 2007) \& (Krippendorff (2012).The negative analysis was undertaken to improve the quality of the content analysis since it sorts out "meaningful absent" characteristics in the materials (Pauwels, 2012). In the research related to the language instructional procedures what is deliberately evaded to describe is as essential as what is openly stated. These unspecified assumptions may not agree with the offered policy suggestions.

\section{Results and Discussion}

\section{Evaluation of National English Curriculum Booklet of Pakistan (NECBP) (2006)}

\section{Introduction}

The NECBP (2006) is the latest copy of the national curriculum and it was implemented in 2010. It is broader in scope than the previous version. Unfortunately, all the textbooks taught at the HSC level are based on the earlier copy of the national curriculum that came into force in 2002. But constructive implications can only be inferred after cautious evaluation of the future inclinations which are planned for English language education in Pakistan.

The NECBP opens with a description of the importance of English in the Pakistani situation; therefore, few motives are suggested to present English as an instructional medium in all institutions of the country. It laid stress on the significance of teaching the English language at the elementary level: With this perspective, the teaching of English has been introduced as a language from grade one and would be used as a medium of instruction across the curriculum for various subjects (NECBP, 2006) 


\section{Content and Approach}

The NECBP offers a 'product aspect' approach that utilizes both skilloriented and knowledge-oriented goals. These aims are mostly elaborated regarding competencies that are sub-divided into standards.The standards contain benchmarks that are purposed to be accomplished on several phases - grade I - XII.Lastly, the SLOs are stated which are based on the description of the benchmarks. Each benchmark has a different number of SLOs. The following figure explains the organizational aspects of the curriculum:

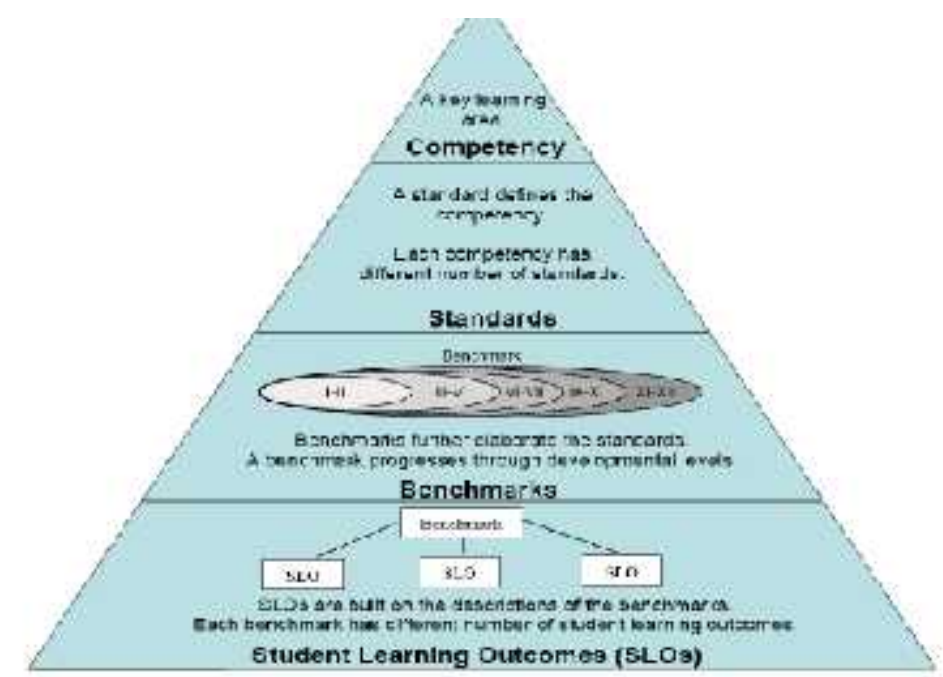

(Adapred from "National Curriculum for Iinglish I anguage: (irades I-XII", 2006: 6 )

Crganization of the Curriculum (2006) Framework

Figure: 2

The curriculum document keeps on mentioning competencies, standards, benchmarks, and SLOs.

It is not possible to discuss all the SLOs in this study since they are mentionfor all grades from grade I to XII separately in detail [see few SLOs in Appendix-B].

The curriculum covers language practice and assessment approach,emphasizing grammar and skill:

The curriculum is designed, particularly, to promote the academic and employment language needs for learners who wish to pursue their higher studies, as well as, for those who might terminate education after grade XII. Consequently, it aims to offer academic and practical skills that learners can use to complete their studies or build their careers after graduating from school (NECBP, 2006). 
It discusses different language proficiencies stressing reading and writing skills. The document also proposes an amalgamation of skills however they are treated separately. Likewise, the document postulates chiefly 'discrete' viewpoint, on the other hand, it puts emphasis on the integration of skills [see Appendix-B]. Additionally, it focuses on accuracy and fluency and so the stress is predominantly on form rather than function while dealing with lexical and operational language aspects.

\section{Task Types and Instructional Method}

The curriculum proposes different activities together with communicative exercises, group talks, dialogues practice, assignments, presentations, and analysis.Cognitive skills, like determining, reasoning, assessing, and inferring, are also discussed in the curriculum especially at the HSC level program. It also supports students' responses. On the other hand, most of the curriculum is implied related to the growth of students' innovative skills except a small number of benchmarks.

The document desires that students must know how to do interpretive activities in which they are asked "to speak, read, write or listen" (ibid, 2006, 150 ), and the task of the teacher is to correct error otherwise he must remain silent.

\section{The Curriculum and the Course Books}

The curriculum booklet declares that the course books are of fundamental values in the Pakistani educational scenario:

A text book remains one of the most extensively used resources in Pakistani classrooms as learning materials are not easily available in some teaching-learning contexts (NECBP2006, 160)

Then again it is proposed that the course book possibly will not be the asset used for assessment. As an alternative, it will contribute to the acquirement of the SLOs listed in the booklet.Whereas, the essentials of this recent function are not specified.As a substitute, there are some proposals for the teachers like they must teach the course book energetically along with the other accessible materials and class activities. This suggestion stresses the need for teachers' training to design their instructional materials.

The document also offers strategies to design a comprehensive course book. The material designers are advised to base their reading-texts on the given SLOs. It is admirable that the course books are suggested to be designed according to the curriculum instead of other resources. But, the booklet must have given some sort of freedom and flexibility in selecting content and themes to the course book authors. 


\section{The Curriculum and the Target Students}

Chiefly, the NECPB 2006 appears to offer recommendations for the professional and academic needs of the learners.First and foremost, it emphasizes the main linguistics features like four language skills, phonology, form, lexis. Further, it proposes focused reading and writing exercises and different tasks centered on reading-texts. The booklet also talks about verbal skills and advises genuine oral exercises centered on a real-life setting like dialogues, group conversations, and debates.

On the other hand, some language aspects of vital importance are disregarded. For instance, activities improving listening skills are not mentioned. Moreover, the booklet expects the learners to listen to radio/TV programs, railway station or airport announcements, and speeches without any practice or training. Also, there appears to be a hidden emphasis on reading and writing proficiencies. Whereas, Aftab (2011) claims that spoken English is demanded in the well-paid jobs in Pakistan.

Furthermore, about $50 \%$ of the topics proposed by the curriculum are didactic rather than teaching language aspects like environment/peace/people, gender discrimination, education, respect of hard struggle. In the same way, at the elementary level, importance is given to Pakistani culture considering that the learners at the primary level may not take interest in the foreign cultures.

If a comprehensive needs analysis had been conducted before the curriculum development, these shortcomings might have been reduced.

\section{The Teaching Scenario}

The target of the NECBP 2006 could be achievable only when a wide-ranging renovation of the teaching scenario with the help of instructors and the administration is done. The document itself states that most of the tutors are inefficient to achieve the set goals due to the lack of training.The curriculum designers believe that instructors' training relating to improving their teaching proficiency will allow them to attain the objectives set in the booklet.This looks simple but it is complicated in the real context. At first, it is not easy to change the attitude of the teachers regarding the booklet; it is possibly a long procedure.Most considerably simply the instructors' training related to understanding the curriculum possibly will not prepare them for integrated approaches and different techniques required to implement the booklet. Therefore, they must be encouraged to obtain genuine skills and competence to improve the linguistics skills of the students according to the stated SLOs and teaching tactics. 


\section{Analysis of Teachers' AttitudeRelating to Curriculum andHSC Course books}

This section presents the teachers' opinion regarding the effectiveness of the curriculum in enhancing learners' linguistics expertise.

\section{Needs Analysis}

Nearly all the respondents (English teachers from different colleges) think that English will be needed for higher studies and well-paid jobs in the country and abroad.They also agreed that the language is also required to carry out official tasks like filling different formal documents, writing business letters, and composing a resume. Only $20 \%$ of the teachers believed that the language is not necessary for acquiring local jobs.

\section{The Benchmarks and Students Learning Outcomes (SLOs)}

The teachers, in the majority, were of the opinion that the NECBP 2006 emphasizes fluency and accurateness. They believe that acquiring adequate grammar knowledge will not assist to accomplish the target (that is to acquire a foreign language).Although the curriculum proposes inclusive directions to improve the language expertise of the learners yet the prescribed course books do not meet the criteria set in the document. Above $80 \%$ of the instructors wishedthat the HSC level course books must be changed. They maintained that the language course books should focus on functional grammar instead of providing information about foreign literature. Moreover, most of the tasks are a discrete-point and integrated approach to teach language skills is ignored. All the respondents claimed that the books do not offer any verbal and listening activities.

\section{Teachers'AttitudeConcerning Recommended Course books for HSC Level}

Merely $15 \%$ of the teachers were contented with the recommended course books at the HSC level. Most of them thought that the books are limiting and do not develop creativity in learners. They demanded that more activities must be added to enhance other linguistic features like vocabulary, syntax, spoken and listening skills. Themes of the reading-text were thought to be restrictive and the addition of wideranging themes, related to the modern world, were advised to gain the attention of the learners.Furthermore, the lexical structure used in the books is not only complicated but also outdated because all the reading-texts are either from the $19^{\text {th }}$ or $20^{\text {th }}$ century.The subject matters associated with daily life are overlooked and few scientific essays are included.

\section{The Course BookSelection Criteria}

All the public sector teachers guaranteed that they have never been part of any course book selection panel. The MEP forms a committee of 10 to 12 members who designed the course book and the book is then prescribed for the whole province afterMEP approves it. This indicates that the authorities overlook the 
esteemed viewpoint of the teachers who perform the role of the bridge between the students and the instructional material (that is, course books). The cited criteria for choosing a course bookare very limiting. This possibly will be thecause that the current course books do not meet the linguistic need of the HSC level learners.

\section{Conclusion}

The current study aimed to determine whether the NECBP prescribed for the HSC level and the course books IETO and IETT based on the same curriculum improvedthe linguistic expertise of the learners studying in the higher secondary government schools and colleges of Karachi. In the light of qualitative data collected from the content analysis of curriculum and interviews of the HSC level teachers, it could be said that the NECBP seems too limiting and inflexible. While SLOs to be accomplished may assist the authors to design a course book with the help of a systematic set of aspects for all the target levels.

The booklet must have offered freedom to choose themes keeping the requirements and interests of both teachers and learners. Italso lacks different teaching tactics and concepts associated with language learning.Then again, it is unviable to recommend surely which linguistic features are assumed to be accomplished at each advanced level. For that reason, expecting the learners to achieve most of the SLOs at the end of each grade seems impractical.

Lastly, the majority of the instructors cited that the current course books IETO and IETT either be revised or changed.They mentioned that the course books are restrictive, less productive, and do not achieve the set targets listed in the English curriculum for the higher secondary level. Only a few teachers, who like to teach language through strict grammatical procedures and discrete-point exercises, supported the course books. Most of them claimed that there are only a couple of tasks thatsuggestincorporation of different language skills. A small number of exercises containing a few compositions, error correction, restating sentences using given words, and information related to phrasal verbs were considered the most supportive parts of the course books. 


\section{References}

Aftab, A. (2011). English Language Textbooks Evaluation in Pakistan. Ph. D thesis, university of Birmingham, pp.203,321-322, 399, 432.

Akram, M. \& Mahmood, A. (2007). The Status and Teaching of English in Pakistan. Languagein India

Ansary, H. \&Babaii, E. (2002). Universal Characteristics of EFL/ESL Textbooks:A Step towards Systematic Textbook Evaluation. The Internet TESL Journal 8/2, pp.12

Berg, B. L. (2001). Qualitative Research Methods for theSocial Sciences (4thEd.). Boston: Allyn and Bacon.

Crowe, S., Cresswell, K., Robertson, A., Huby, G., Avery, A., \& Sheikh, A. (2011). The case study approach. https:/ / doi.org/10.1186/1471-2288-11-100

Cunningsworth, A. (1984). Evaluating and Selecting EFL Materials. London: Heinemann

Dörnyei, Z. (2007). Research Methods in AppliedLinguistics. Oxford: Oxford University Press

Dubin, F. \& Olshtain, E. (1986) Course Design. New York: Cambridge University Press

Finney, D. (2002).The ELT Curriculum: A Flexible Model for a Changing World. In Richards, J. C., \& Renandya, W. A. (eds.) Methodology in Language Teaching: An Anthology of Current Practice. Cambridge: Cambridge University Press

Graddol, D. (1997). The future of English? A guide to forecasting the popularity of the English language in the 21st century. British Council

Grant, N. (1987). Making the most of your textbook. London: Longman Inc.

Krippendorff, K. (2012). Content Analysis: AnIntroduction to its Methodology (3rdEdn). California: Sage

McGrath, I. (2002). Materials evaluation and design for language teaching. Edinburgh University Press

Naseem, S., Shah, S.K. \& Tabassum, S. (2015). Evaluation of English Textbook in Pakistan: A Case Study of Punjab textbook for 9th class. European Journal of English Language and Literature Studies Vol.3, No.3, 24-42. 
Nazeer, M., Shah, S. K. \&Sarwat Z. (2015). Evaluation of Oxon English Textbook Used in Pakistan Public Schools for 6th \& 7th Grade. Macrothink Institute

Pakistan. Federal Ministry of Education (2006)National Curriculum for the English Language Grades I-XIIwww.moe.gov.pk/English Language-I-XII.pdf

Pakistan. Federal Ministry of Education (2008) Draft of National Education Policy, www.moe.gov.pk.pdf

Pauwels, L. (2012). A multimodal framework for analyzing websites as cultural expressions. Journal ofComputer-Mediated Communication, 17(3), pp. 247265.https://doi.org/10.1111/j.1083-6101.2012.01572.x

Rabbini, R. (2002). An Introduction to Syllabus Design and Evaluation. The Internet TESL Journal, VIII (5), 4-10. http:/ / iteslj.org/Articles/Rabbini-Syllabus.html

Schreier, M. (2012). Qualitative Content Analysis inPractice. London, UK: Sage, pp.190191.

Smith, M. K. (2000). Curriculum theory and practicehttp://www.infed.org/biblio/bcurric.htm

Tobin, R. (2010). Descriptive case study. In Mills, A. J., Durepos, G., \&Wiebe, E. (Eds.), Encyclopedia of CaseStudy Research, 289-290. Thousand Oaks: Sage.

White, R. (1988). The ELT Curriculum. Oxford, Blackwell

Xiaotang, C. (2011). Current Trends in Syllabus Design and Materials Development, SCRIBD

\section{Evaluated Textbooks}

Morgan, D. Y. (Ed). (2012). The Intermediate English: Book One (Class XI), Jamshoro, Sindh Textbook Board.

Noonari, A. F. (Ed). (2008). The Intermediate English: Book Two (Class XII), Jamshoro, Sindh Textbook Board. 